\title{
Study of Self-Tuning PI Controllers in a Constant Voltage Control System for Doubly-fed Wind Turbines
}

\author{
Bo Gu*, Xiaodan LI, Lingyun Zhang and Daoyin Qiu
}

Institute of Electric Power, North China University of Water Resources and Electric Power, Zhengzhou 450011, China

\begin{abstract}
The doubly-fed induction generator (DFIG) produces the reactive power to maintain its constant voltage operation. Firstly, the principle of the constant voltage control system for double-fed wind turbines is researched, and the influence on DFIG terminal voltage when the wind speed changes and the grid voltage sags is analyzed. Secondly, self-tuning PI control algorithm based on BP neural network is proposed. This algorithm realizes the dynamic setting of PI parameters in the process of wind speed change and grid voltage sag, and then builds a simulation model of the system. The simulation results show that the constant voltage control system using the dynamic setting of PI parameters based on BP neural network has improved the stability of grid-connected voltage for doubly-fed wind turbines and reduced the response time in the process of wind speed change and grid voltage sag.
\end{abstract}

Keywords: Doubly-fed Wind Turbines, constant voltage control system, BP neural network, Self-tuning PI controller.

\section{INTRODUCTION}

Wind energy is a clean and renewable energy. Under the condition of today's energy shortage and environment problem, wind power generation has been paid more and more attention. The output power of wind turbines is affected by wind speed. Due to the characteristics of randomness and variability of wind speed, the output power of wind turbine changes with time. At the same time the wind farms are commonly located in remote areas, so the change of its out power poses an adverse affect on the stability of the gridconnected voltage for wind farms. For a higher proportion of wind farms in power system, the disconnection of wind turbines may cause the collapse of the grid voltage and frequency when the grid voltage drops to a certain value, and that may bring many adverse consequences [1]. Technical rule for connecting a wind farm to a power network explicitly requests that the reactive power-voltage control system should be configured in grid-connection wind farm, and this system controls the grid-connection voltage at the rated voltage of 97 percents to 107 percents.

The power electronic converter is used in doubly-fed wind turbines, and this converter can make doubly-fed wind turbines maintain the required power factor or voltage $[2,3]$. Therefore, DFIG has two operation modes which are constant power factor control and constant voltage control. The doubly-fed wind turbines used constant voltage control mode which can provide support for the stability of the grid voltage $[4,5]$. The strategy is presented which uses the $\mathrm{Ny}$

*Address correspondence to this author at the Institute of Electric Power, North China University of Water Resources and Electric Power, Zhengzhou 450011, China; Tel: 0371-65790488; Fax: 0371-65790488;

E-mail: gb1982@ncwu.edu.cn quist constraint algorithm to design optimization PI controller [6]. But this algorithm cannot realize the adaptive control of DFIG terminal voltage in case of the wind speed changing and the grid power failure. A method based on dynamic reactive power compensation to solve the problem of gridconnected voltage fluctuations for wind farm was proposed in [7]. An unbalanced grid voltage appeared in the grid will cause an oscillation of the DFIG's electromagnetic torque and stator instantaneous power, so a vector proportionalintegral control method was presented which was used to eliminate the torque and stator power oscillation [8]. The reactive power control strategy for doubly-fed wind turbines when the grid voltage rises or drops is discussed in $[9,10]$, and a control method that compensates unbalanced grid voltage by injecting negative sequence current into the grid side converter is presented, which has improved the stability of grid-connected wind farm. A direct power control strategy based on discrete space vector modulation was presented in [11]. So no extra power and current control loops were required when doubly-fed wind turbines used this control strategy, and this simplified system model minimized the range of voltage fluctuation. A control strategy that uses the equivalent wind speed as feed forward to improve the constant voltage control is presented in [12], which has effectively suppress the voltage fluctuations due to the change of wind speed. The above authors have being studied many methods to solve the problem of grid-connected voltage fluctuations. Although the PI parameters optimization of the constant voltage control system above do not need additional reactive power compensation device the performance of the voltage control system, their study were mainly in achieving the optimal PI parameters of the constant voltage control system in the steady state. Whether the PI controller parameters need to be adjusted dynamically and how to be adjusted in changing wind speed and grid voltage drooping state, these authors did not give definitive conclusions. 


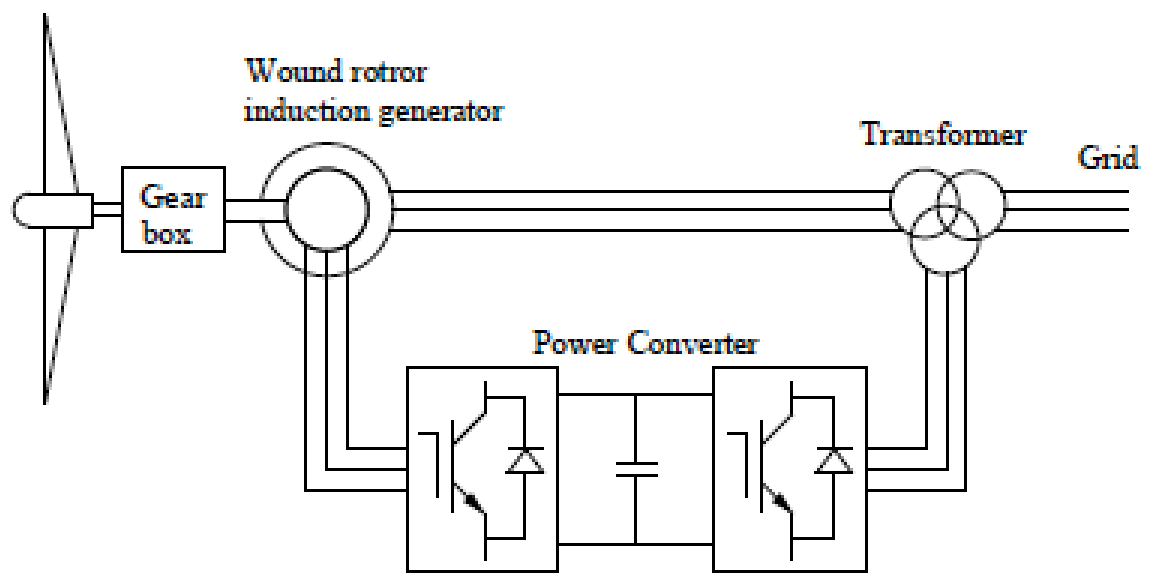

Fig. (1). Typical configuration of a DFIG wind turbine.

In the process of actual operation, the doubly-fed wind turbines terminal voltage is influenced by the change of wind speed, grid operation and other aspects. Firstly the principle of constant voltage control system for doubly-fed wind turbines has been studied, and then analyzed the influence on DFIG terminal voltage when the wind speed changes and the grid voltage sags. Secondly, self-tuning PI control algorithm based on BP neural network is proposed, and established the simulation model of system. As known from the simulation results, the self-tuning PI control algorithm based on BP neural network has improved the stability of grid-connection voltage for doubly-fed wind turbines, and reduced the response time. The control effect is further improved.

\section{DOUBLY-FED INDUCTION GENERATOR WIND TURBINE}

A typical configuration of a DFIG wind turbine is shown in Fig. (1). The doubly-fed induction generator wind turbine can realize the variable-speed operation due to the power electronic converters interface, allowing a full decoupling from the grid.

The DFIG is a wound rotor induction generator with the stator windings connected directly to the three-phase, constant-frequency grid and the rotor windings connected to a back-to-back voltage source converter. Thus, the term "doubly-fed" comes from the fact that a DFIG can deliver power to the grid through the stator and rotor, while the rotor can also absorb power from the grid. This depends on the rotational speed of the generator.

The power electronics converter comprises of two IGBT converters, namely the rotor side and the grid side converter, connected with a direct current link. The rotor side converter controls the generator in terms of active and reactive power, while the grid side converter controls the direct current link voltage and ensures operation at a large power factor.

\section{THE STEADY STATE MATHEMATICAL MODEL OF DOUBLY-FED INDUCTION GENERATOR}

With generator convention, the establishment of DFIG steady-state mathematical model in synchronous rotation $d$, $q, O$ coordinate can derived the equations of the steady-state voltage and flux equations [13].

$$
\begin{aligned}
& \left\{\begin{array}{l}
U_{d s}=-r_{s} I_{d s}-\psi_{q s} \\
U_{q s}=-r_{s} I_{q s}+\psi_{d s} \\
U_{d r}=r_{s} I_{d r}-s \psi_{q r} \\
U_{q r}=r_{r} I_{q r}+s \psi_{d r}
\end{array}\right. \\
& \left\{\begin{array}{l}
\psi_{d s}=-L_{s s} I_{d s}+L_{m} I_{d r} \\
\psi_{q s}=-L_{s s} I_{q s}+L_{m} I_{q r} \\
\psi_{d r}=L_{r r} I_{d r}-L_{m} I_{d s} \\
\psi_{q r}=L_{r r} I_{q r}-L_{m} I_{q s}
\end{array}\right.
\end{aligned}
$$

In the formula above, $U_{d s}$ and $U_{q s}$ are $d q$ axis component of the stator voltage; $U_{d r}$ and $U_{q r}$ are $d q$ axis component of the rotor applied voltage. $I_{d s}$ and $I_{q s}$ are $d q$ axis component of the stator winding current; $I_{d r}$ and $I_{q r}$ are $d q$ axis component of the rotor winding current. $\psi_{d s}$ and $\psi_{q s}$ are $d q$ axis component of the stator flux; $\psi_{d r}$ and $\psi_{q r}$ are $d q$ axis component of the rotor flux. $s$ is the slip ratio of DFIG, $L_{r r}=L_{r}+L_{m}, L_{s s}=$ $L_{s}+L_{m}$. Put the synchronous rotation axes on the stator synthetic flux, therefore, the stator flux $\psi_{s}$ is equal to $\psi_{d s}$ and $\psi_{q s}$ $=0$. In the case of stator resistance is ignored, the following equations can be derived.

$\left\{\begin{array}{l}U_{d s}=0 \\ U_{q s}=U_{s}\end{array}\right.$

According to the first two equations in (2), the current relationship of the stator and rotor can be drawn as follows.

$$
\left\{\begin{array}{l}
I_{q s}=-\frac{L_{m}}{L_{s s}} I_{q r} \\
I_{d s}=-\frac{U_{s}}{L_{s s}}+\frac{L_{m}}{L_{r r}} I_{d r}
\end{array}\right.
$$

The equations of the active and reactive power in stator side can be expressed as the formula (5).

$$
\left\{\begin{array}{l}
P=U_{d s} I_{d s}+U_{q s} I_{q s}=U_{s} I_{q s} \\
Q_{s}=U_{q s} I_{d s}-U_{d s} I_{q s}=U_{s} I_{d s}
\end{array}\right.
$$




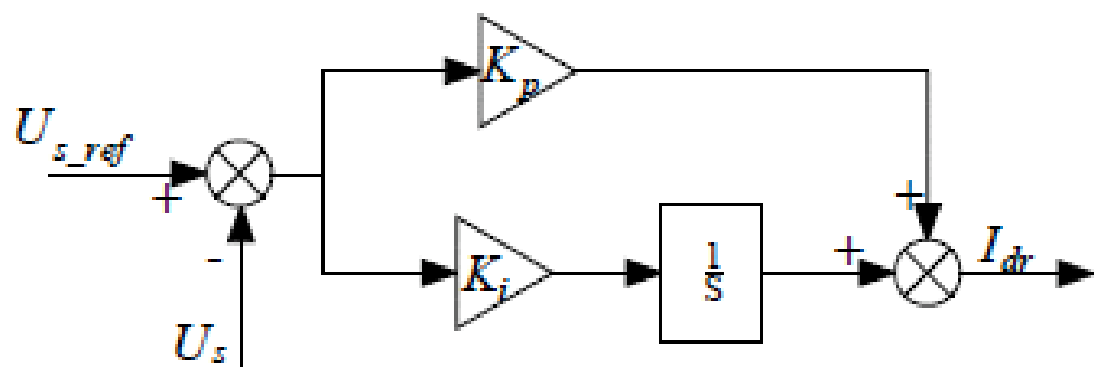

Fig. (2). Schematic diagram of the constant voltage control system.

From the stator flux oriented vector control model of DFIG above it can be assumed that the active and reactive power of stator side can be adjusted by controlling the $d q$ axis component of rotor side current, to realize the decoupling control of power.

\section{THE BASIC PRINCIPLE OF THE CONSTANT VOLTAGE CONTROL SYSTEM}

From the analysis above, the stator flux oriented vector control of DFIG have realized the power decoupling control. Therefore, the rotor side converter in DFIG has been used to control the terminal voltage. The reactive power $Q_{\text {grid }}$ conveyed to the grid from wind farm can be derived by formula (4) and (5).

$Q_{\text {grid }}=Q_{s}=U_{s} I_{d s}=-\frac{U_{s}^{2}}{L_{s s}}+\frac{L_{m} U_{s}}{L_{s s}} I_{d r}$

The rotor current component $I_{d r}$ in the formula (6) is divided into a generator magnetizing component $I_{d r} m$ and a component for controlling reactive power flow with the connecting network $I_{d r} g$. The total reactive power is also divided into $Q_{m a g}$ and $Q_{g e n}$. Hence the formula (7) can be expressed as:

$$
\left\{\begin{array}{l}
Q_{m a g}=-\frac{U_{s}^{2}}{L_{s s}}+\frac{L_{m} U_{s}}{L_{s s}} I_{d r_{-} m} \\
Q_{g e n}=\frac{L_{m} U_{s}}{L_{s s}} I_{d r_{-} g}
\end{array}\right.
$$

As the terminal voltage will increase or decrease when more or less reactive power is delivered to the grid, the voltage control should fulfill the following requirements:

(i) The reactive power consumed by the DFIG should be compensated by $I_{d r_{-} m}$.

(ii) If the terminal voltage is too low or too high compared with the reference value then $I_{d r_{g}}$ should be adjusted appropriately.

Therefore, in constant voltage control mode $I_{d r_{-} g}$ can make corresponding adjustment to raise or reduce the reactive power when the grid voltage has a little change, so as to maintain the terminal voltage approximately constant. The schematic diagram of the constant voltage control system is shown in Fig. (2), from which, $U_{s}$ is the DFIG terminal voltage, and $U_{s_{-} \text {ref }}$ is the reference value for the terminal voltage of the DFIG. Make $U_{s_{-}} r f=1 \mathrm{pu}$ in the simulation.

\section{THE SYSTEM STABILITY BASED ON NYQUIST'S STABILITY CRITERION}

The operation of each turbine in the wind farm should be taken into account to ensure that all power electronic converters operate in the allowable region. To ensure whether the control system operates under the changing conditions, a design technique based on the Nyquist's stability criterion is used to tune the controller gains. So, a primary requirement for a PI controller design is that the parameters of the controller are chosen in such a way that the closed-loop system is stable. A PI controller of the form can be expressed as follow.

$C(s)=K_{p}+\frac{K_{i}}{s}$

The formula (8) has two parameters, and the stability region can be represented by an area in two dimensions. To describe this area a transfer function of a plant model is represented as the formula (9).

$P(j \omega)=r(\omega) e^{j \phi(\omega)}=r(\omega)(\cos (\omega)+j \sin (\omega))$

Therefore, the closed-loop transfer function can be expressed as (10), and the Nyquist curve of it as shown in the Fig. (3).

$C_{l}(j \omega)=P(j \omega) C(j \omega)=r(\omega)(\cos (\omega)+j \sin (\omega))\left(K_{p}-j \frac{K_{i}}{\omega}\right)$

$\mathrm{M}_{\mathrm{s}}$ in the figure is sensitivity gain. In order to guarantee the system stability, it is desirable that $C_{l}(j \omega)$ stays as far away from the -1 point as possible. By the Nyquist's stability criterion, the following equation can be derived.

$r(\omega)(\cos (\omega)+j \sin (\omega))\left(K_{p}-j \frac{K_{i}}{\omega}\right)=-1$

Separating the real and imaginary part we find that the boundary of stability region can be represented parametrically as

$$
\left\{\begin{array}{l}
K_{p}=-\frac{\cos \phi(\omega)}{r(\omega)} \\
K_{i}=-\frac{\omega \sin \phi(\omega)}{r(\omega)}
\end{array}\right.
$$




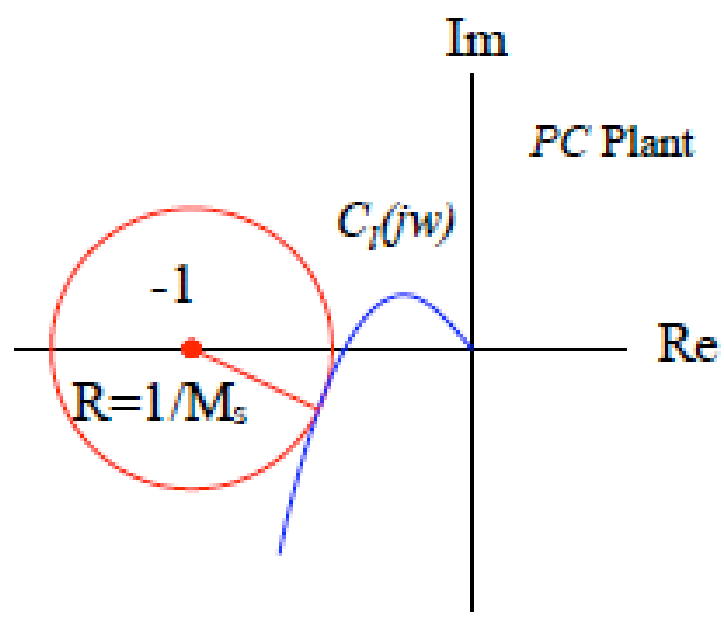

Fig. (3). Nyquist curve of the loop transfer function.

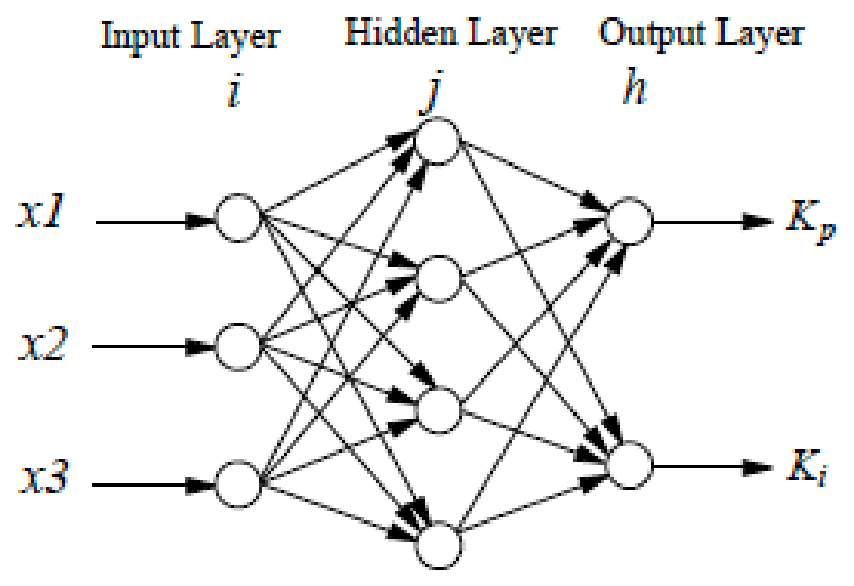

Fig. (4). Structure of three layers BP neural network.

In (12), $r$ is the magnitude of the transfer function, and $R=1 / M_{s}$ defines the sensitivity peak. By differentiating $K_{i}$ with respect to $\omega$ in (12) under the wind speed change or grid failure condition, an optimal value $\omega_{0}$ can be computed by solving (13) subject to (14) and (15) [14].

$J=\min _{\left(\omega_{0}\right)}\left[\left(R+\sin \left(\phi\left(\omega_{0}\right)\right)\right)\left(\frac{\dot{r}\left(\omega_{0}\right)}{r\left(\omega_{0}\right)}-\frac{1}{\omega_{0}}\right)-\phi\left(\omega_{0}\right) \cos \left(\phi\left(\omega_{0}\right)\right)\right]$

Subject to

$\omega_{90^{\circ}}<\omega_{0}<\omega_{\left(180^{\circ}-\arcsin (R)\right)}$

For the positive $K_{i}$ and $K_{p}$

$\frac{d^{2}}{d \omega_{0}^{2}}\left\{\left|1+\left(K_{p}-\frac{j}{\omega_{0}} K_{i}\right) P\left(j \omega_{0}\right)\right|^{2}\right\} \geq 0$

Where $\phi(\omega)$ is the phase function of the transfer function.

\section{THE PRINCIPLE OF SELF-TUNING PI CON- TROLLER BASED ON BP NEURAL NETWORK}

\subsection{The Structure and Principle of BP Neural Network}

This paper adopts three layers BP neural network and its structure is shown in Fig. (4).
This BP neural network consists of input layer, hidden layer and output layer nodes, the weight coefficient connects front layer and back layer [15]. $V=\left[v_{i j}\right]_{\mathrm{n} \times \mathrm{m}}$ is the weight matrix between input layer and hidden layer, and $W=\left[w_{j h}\right]_{m \times l}$ is the weight matrix between hidden layer and output layer. Where $n$ is the number of input layer nodes, $m$ is the number of hidden layer nodes, $l$ is the number of output layer nodes. The number of $n$ is determined by the complexity of the controlled object. The number of $m$ is about 2 times of the input layer nodes. The number of $h$ is 2 which stand for two output parameters $K_{p}$ and $K_{i}$.

The output value of network's input layer is:

$O_{i}^{(1)}=x(i) \quad(i=1,2, \cdots, n)$

The input and output values of network's hidden layer are as follows:

$$
\left\{\begin{array}{l}
n e t_{j}^{(2)}(k)=\sum_{i=0}^{n} V_{i j}^{(2)} O_{i}^{(1)} \\
O_{j}^{(2)}(k)=f\left(n e t_{j}^{(2)}(k)\right) j=1,2, \cdots m
\end{array}\right.
$$

In the formula (17), the superior (1), (2), (3) respectively represent the input layer, the hidden layer and the output layer. 


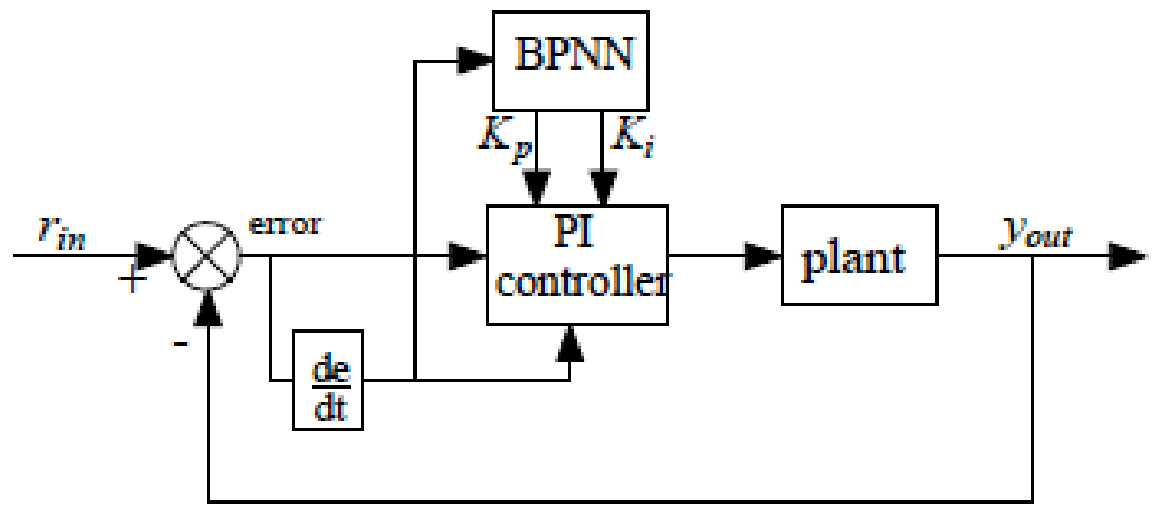

Fig. (5). Structure of self-tuning PI controller based on BP neural network.

The positive-negative symmetrical sigmoid function is taken as the transfer function of the hidden layer nodes, so that the output of the whole network is limited in a small range.

$$
f(x)=\tanh (x)=\frac{e^{x}-e^{-x}}{e^{x}+e^{-x}}
$$

The input value and output value of network's output layer are as follows:

$$
\left\{\begin{array}{l}
n e t_{h}^{(3)}(k)=\sum_{j=0}^{m} w_{j h}^{(3)} O_{j}^{(2)}(k) \\
O_{h}^{(3)}(k)=g\left(n e t_{h}^{(3)}(k)\right) \quad(h=1,2) \\
O_{1}^{(3)}(k)=K_{p} \\
O_{2}^{(3)}(k)=K_{i}
\end{array}\right.
$$

Due to the fact that $K_{p}$ and $K_{i}$ can not be negative, the non-negative sigmoid function is taken as the transfer function of the output layer nodes.

$g(x)=\frac{1}{2}(1+\tanh (x))=\frac{e^{x}}{e^{x}+e^{-x}}$

The performance index function can be expressed as:

$$
E(k)=\frac{1}{2}\left(r_{\text {in }}(k)-y_{\text {out }}(k)\right)^{2}
$$

The weight coefficient are modified using gradient descent method, namely, the search adjustment of $E(k)$ to weight coefficient along its negative gradient direction and attach a inertia term make the search quickly converge to the global minimum.

$\Delta w_{j h}^{(3)}(k)=-\eta \frac{\partial E(k)}{\partial w_{j h}^{(3)}}-\alpha \Delta w_{i j}^{(3)}(k-1)$

In the formula (22), $\eta$ is the learning efficiency, $\alpha$ is the inertial coefficient. The design of BP neural network in this paper make $\eta=0.25$ and $\alpha=0.05$.

Then the corrected weight coefficient can be expressed as

$$
w_{j h}^{(3)}(k+1)=w_{j h}^{(3)}(k)+\Delta w_{j h}^{(3)}(k)
$$

When BP neural network is learning, the input signal ( $x 1$, $x 2$ and $x 3$ ) is transferred from the input layer through hidden layer to the output layer (forward propagation). If the output layer gets the desired output then the learning algorithm will end, or back propagation. Back propagation is calculating the error signal along the original connect direction, adjusting the connection weights of each neuron by using gradient descent method, reducing the error signal.

\subsection{Self-tuning PI Controller Based on BP Neural Net- work}

The classical PI controller has been widely used because of its simple design process, easy realization and good effect [16]. But the classical PI controller has poor adaptability for the operating conditions in actual industrial applications. In order to get better control effect, it is critical that $K_{p}$ and $K_{i}$ realize the self-tuning by searching for the appropriate control algorithm. BP neural network is currently the most widely used neural network, and has skill of arbitrary nonlinear .So BP neural network can achieve optimal PI control by learning the system performance [17].

The structure of self-tuning PI controller based on BP neural network is shown in Fig. (5). Where the BPNN module has achieved the dynamic tuning of the PI controller, plant is the control object.

From the analysis above the steps of dynamically tuning PI controller based on BP neural network PI parameters are as follows.

(i) To determine the structure of BP neural network, that is to determine the number of input layer nodes $n$ and the number of hidden layer nodes $m$, to give the initial matrix $v_{i j}^{(l)}(0)$ and $w_{j h}^{(2)}(0)$ of each layer, and to selected the learning rate $\eta$ and the inertia coefficient $\alpha . k$ is the number of training time, make $k=1$ at the first time training.

(ii) To collect the signal $r_{i n}(k)$ and $y_{\text {out }}(k)$, and calculate the error of the current training times $e(k)=r_{\text {in }}(k)-y_{\text {out }}(k)$.

(iii) Computing the input and output values of each network layers, and the output values of output layer $K_{p}$ and $K_{i}$ are the control parameters of PI controller.

(iv) Calculating the output value of PI controller.

(v) To make the neural network learning, and adjust the weighting coefficient online to realize adaptive adjustment of the PI controller. 


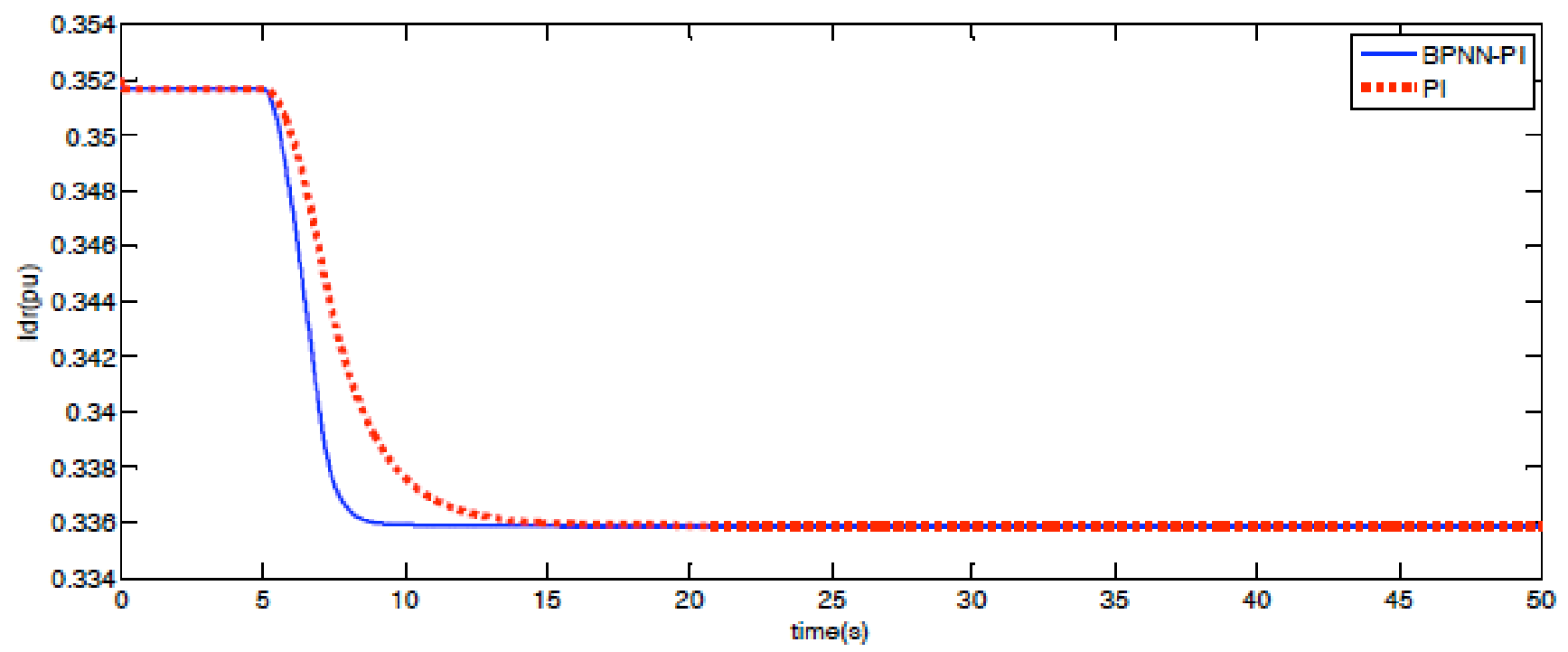

Fig. (6). The Dynamic Change Diagram of $I_{d r}$ When Wind Speed Changes from $8 \mathrm{~m} / \mathrm{s}$ to $10 \mathrm{~m} / \mathrm{s}$.

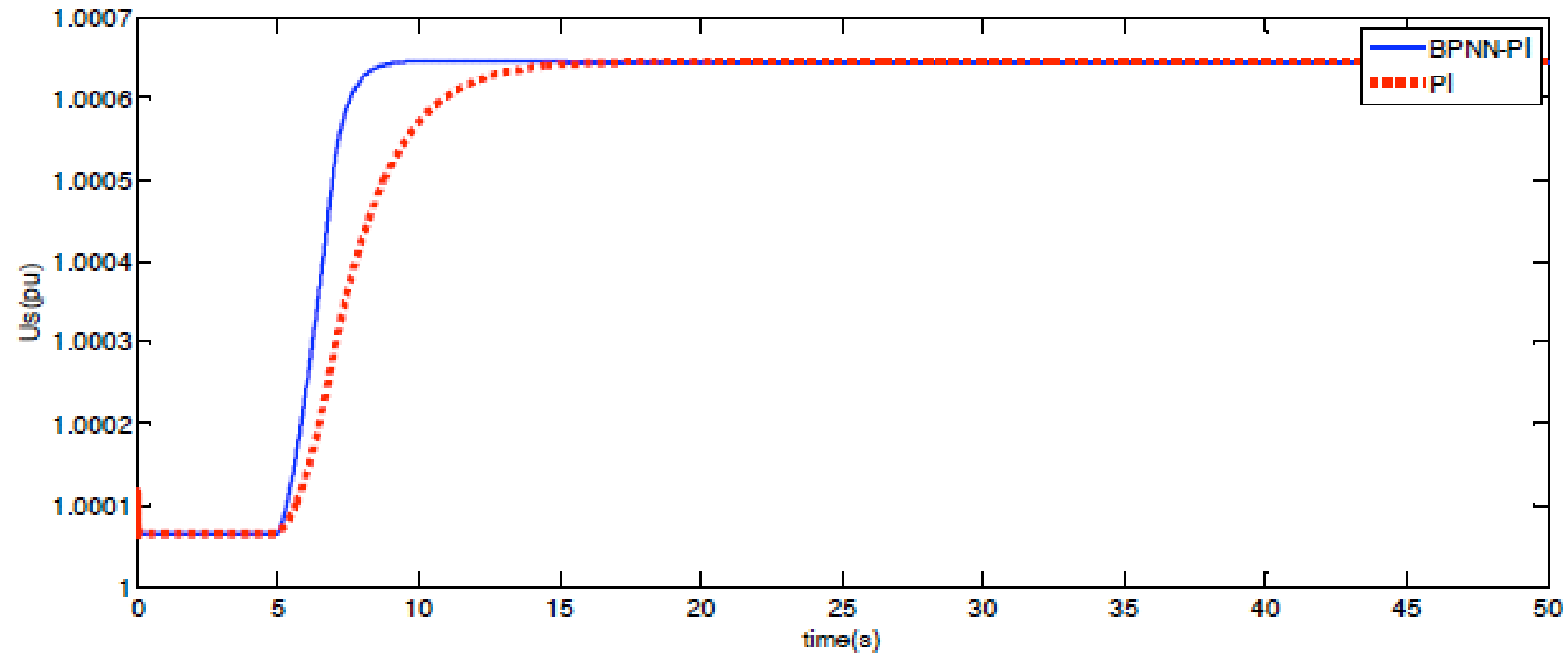

Fig. (7). The dynamic change diagram of $U_{s}$ when wind speed changes from $8 \mathrm{~m} / \mathrm{s}$ to $10 \mathrm{~m} / \mathrm{s}$.

(vi) Making $k=k+1$, and then return to (i).

\section{RESULTS AND DISCUSSION}

Based on the theory above to build a simulation model of the wind turbines connected with the grid. The capacity of a doubly-fed wind turbine is $1.5 \mathrm{MW}$ and its terminal voltage is $575 \mathrm{~V}$. The step-up transformer makes the $575 \mathrm{~V}$ rise to $25 \mathrm{kV}$, and after $30 \mathrm{~km}$ transmission line $25 \mathrm{kV}$ has increased to $120 \mathrm{kV}$ by the second step-up transformer, and then supplies the power to $120 \mathrm{kV}$ grid. The reference voltage of terminal voltage has maintained at $1 \mathrm{pu}$ in the simulation model. The simulation analysis has been done respectively using self-tuning PI control algorithm and classical PI control algorithm in case of wind speed change and grid voltage sag at $t=5 \mathrm{~s}$.

When the wind speed changes from $8 \mathrm{~m} / \mathrm{s}$ to $10 \mathrm{~m} / \mathrm{s}$ at $t=5 \mathrm{~s}$, the dynamic change diagram of rotor current $I_{d r}$ is shown in Fig. (6). The solid line corresponds to the selftuning PI control algorithm based on the BP neural network and its tuned parameters are $K_{p}=5$ and $K_{i}=400$. The dotted line corresponds to the classical PI control algorithm and its parameters are $K_{p}=1.25$ and $K_{i}=300$.

The simulation results shown that when the wind speed changes from $8 \mathrm{~m} / \mathrm{s}$ to $10 \mathrm{~m} / \mathrm{s}$ at $t=5 s$, the self-tuning PI control algorithm based on the BP neural network makes the response time of $I_{d r} 6.60 \mathrm{~s}$ earlier than the classical PI control algorithm. When the wind speed stabilizes at $10 \mathrm{~m} / \mathrm{s}$, the system recovers stability and the rotor current stabilizes at $0.336 \mathrm{pu}$ with a fast and a smooth response for self-tuning PI control algorithm.

When the wind speed changes from $8 \mathrm{~m} / \mathrm{s}$ to $10 \mathrm{~m} / \mathrm{s}$ at $t=5 \mathrm{~s}$, the dynamic change diagram of terminal voltage $U_{s}$ for wind turbines is shown in Fig. (7). The solid line corresponds to the self-tuning PI control algorithm based on the BP neural network and its tuned parameters are $K_{p}=5$ and $K_{i}$ $=400$. The dotted line corresponds to the classical PI control algorithm and its parameters are $K_{p}=1.25$ and $K_{i}=300$. 


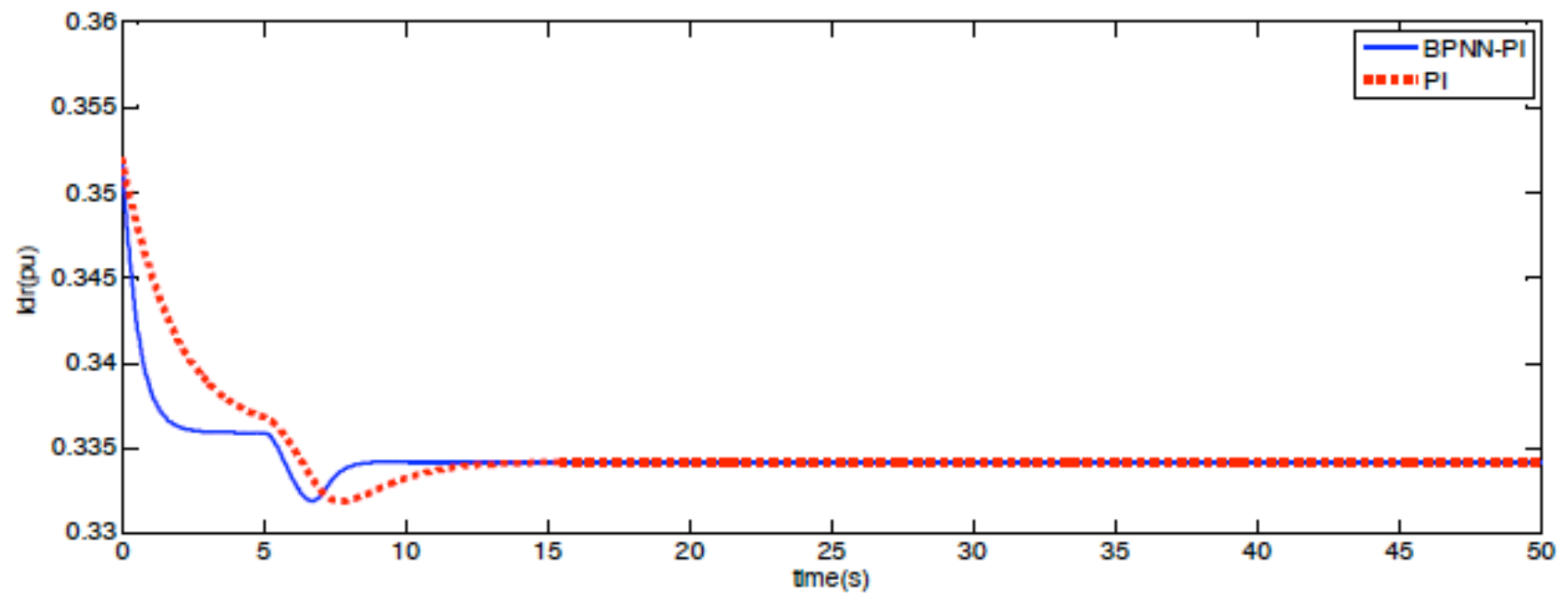

Fig. (8). The dynamic change diagram of $I_{d r}$ when wind speed changes from $10 \mathrm{~m} / \mathrm{s}$ to $12 \mathrm{~m} / \mathrm{s}$.

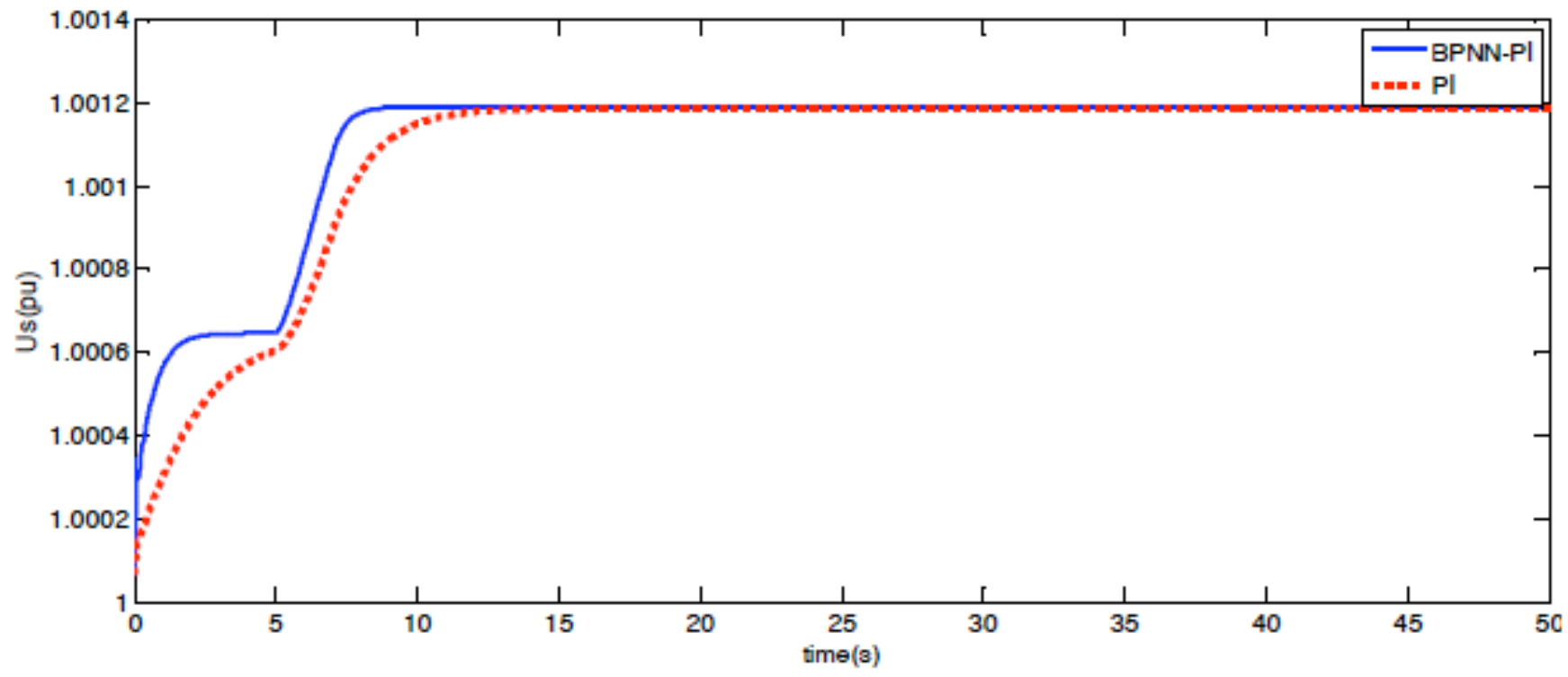

Fig. (9). The dynamic change diagram of $U_{s}$ when wind speed changes from $10 \mathrm{~m} / \mathrm{s}$ to $12 \mathrm{~m} / \mathrm{s}$.

The simulation results show that when the wind speed changes from $8 \mathrm{~m} / \mathrm{s}$ to $10 \mathrm{~m} / \mathrm{s}$ at $t=5 \mathrm{~s}$, the self-tuning PI control algorithm based on the BP neural network makes the response time of $U_{s} 6.72 \mathrm{~s}$ earlier than the classical PI control algorithm. When the wind speed stabilizes at $10 \mathrm{~m} / \mathrm{s}$, the system recovers stability and the terminal voltage stabilizes at $1.00065 \mathrm{pu}$ with a fast and a smooth response for self-tuning PI control algorithm.

When the wind speed changes from $10 \mathrm{~m} / \mathrm{s}$ to $12 \mathrm{~m} / \mathrm{s}$ at $t=5 \mathrm{~s}$, the dynamic change diagram of rotor current $I_{d r}$ is shown in Fig. (8). The solid line corresponds to the selftuning PI control algorithm based on the BP neural network and its tuned parameters are $K_{p}=5$ and $K_{i}=300$. The dotted line corresponds to the classical PI control algorithm and its parameters are $K_{p}=1.25$ and $K_{i}=300$.

The simulation results shown that when the wind speed changes from $10 \mathrm{~m} / \mathrm{s}$ to $12 \mathrm{~m} / \mathrm{s}$ at $t=5 \mathrm{~s}$, the self-tuning PI control algorithm based on the BP neural network makes the response time of $I_{d r} 6.14 \mathrm{~s}$ earlier than the classical PI control algorithm. When the wind speed stabilizes at $12 \mathrm{~m} / \mathrm{s}$, the system recovers stability and the rotor current stabilizes at $0.3342 \mathrm{pu}$ with a fast and a smooth response for self-tuning PI control algorithm.

When the wind speed changes from $10 \mathrm{~m} / \mathrm{s}$ to $12 \mathrm{~m} / \mathrm{s}$ at $t=5 \mathrm{~s}$, the dynamic change diagram of terminal voltage $U_{s}$ for wind turbines is shown in Fig. (9). The solid line corresponds to the self-tuning PI control algorithm based on the BP neural network and its tuned parameters are $K_{p}=5$ and $K_{i}$ $=300$. The dotted line corresponds to the classical PI control algorithm and its parameters are $K_{p}=1.25$ and $K_{i}=300$.

The simulation results show that when the wind speed changes from $10 \mathrm{~m} / \mathrm{s}$ to $12 \mathrm{~m} / \mathrm{s}$ at $t=5 \mathrm{~s}$, the self-tuning PI control algorithm based on the BP neural network makes the response time of $U_{s} 5.22 \mathrm{~s}$ earlier than the classical PI control algorithm. When the wind speed stabilizes at $12 \mathrm{~m} / \mathrm{s}$, the system recovers stability and the terminal voltage stabilizes at $1.0012 \mathrm{pu}$ with a fast and a smooth response for self-tuning PI control algorithm. 


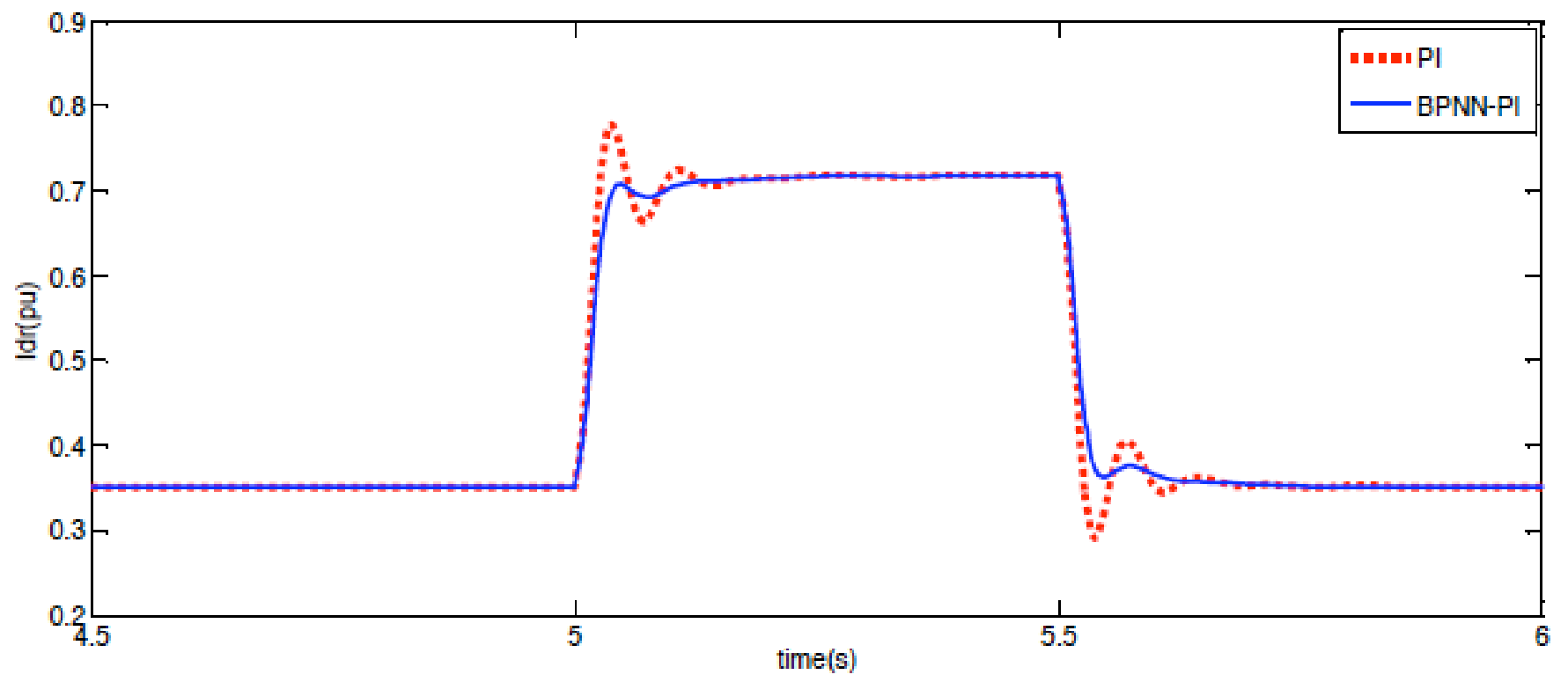

Fig. (10). The dynamic change diagram of $I_{d r}$ when the grid voltage drops $0.1 \mathrm{pu}$.

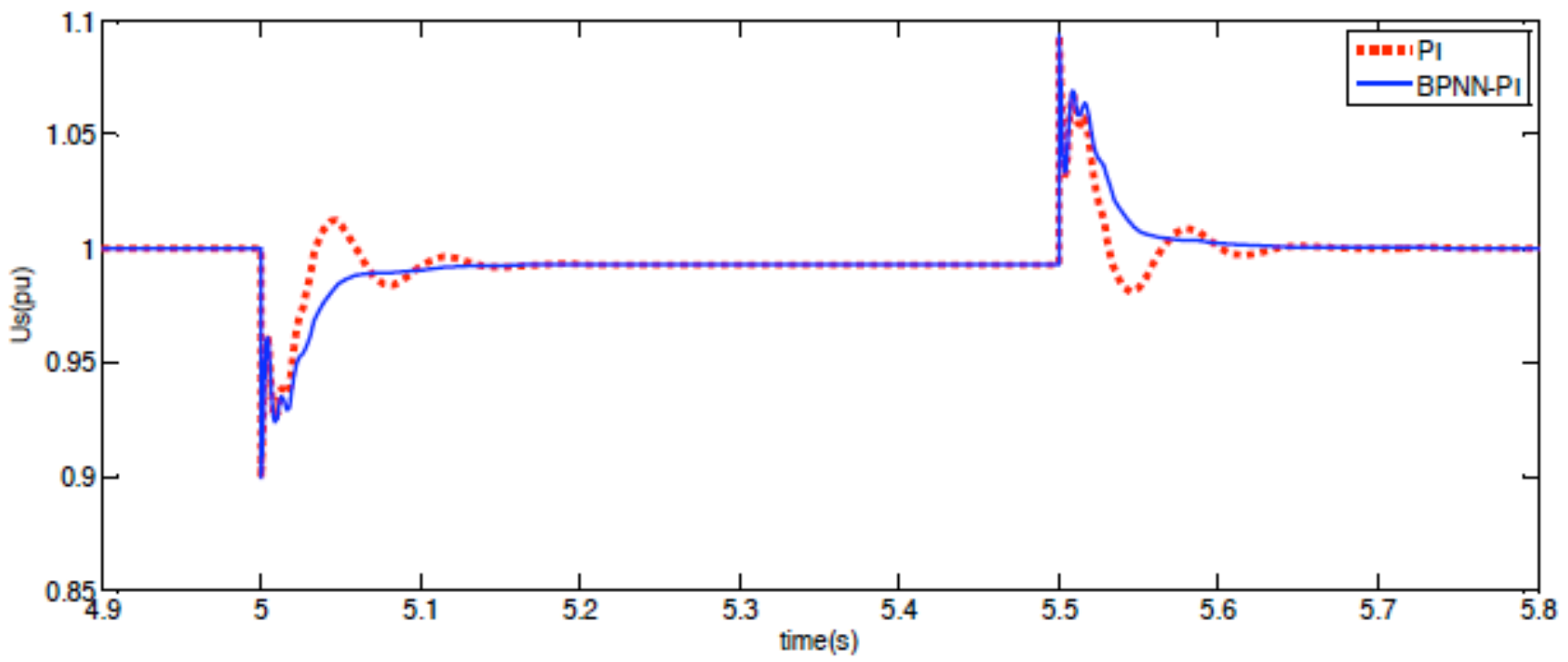

Fig. (11). The dynamic change diagram of $U_{s}$ when the grid voltage drops $0.1 \mathrm{pu}$.

When the grid voltage drops $0.1 \mathrm{pu}$ at $t=5 \mathrm{~s}$ with a duration of $0.5 \mathrm{~s}$, the dynamic change diagram of rotor current $I_{d r}$ is shown in Fig. (10). The solid line corresponds to the selftuning PI control algorithm based on the BP neural network and its tuned parameters are $K_{p}=1.25$ and $K_{i}=150$. The dotted line corresponds to the classical PI control algorithm and its parameters are $K_{p}=1.25$ and $K_{i}=300$.

The simulation results shown that compared with the classical PI control algorithm, the self-tuning PI control algorithm based on the BP neural network has improved the dynamic response characteristics of $I_{d r}$ and reduced the response time when the grid voltage drops $0.1 \mathrm{pu}$. When the fault is cleared after $0.5 \mathrm{~s}$, the system recovers stability and the rotor current recovers the pre-fault state with a fast and a smooth response for self-tuning PI control algorithm.

When the grid voltage drops $0.1 \mathrm{pu}$ at $t=5 \mathrm{~s}$ with a duration of $0.5 \mathrm{~s}$, the dynamic change diagram of terminal voltage $U_{s}$ for wind turbines is shown in Fig. (11). The solid line corresponds to the self-tuning PI control algorithm based on the BP neural network and its tuned parameters are $K_{p}=1.25$ and $K_{i}=150$. The dotted line corresponds to the classical PI control algorithm and its parameters are $K_{p}=1.25$ and $K_{i}$ $=300$.

The simulation results shown that compared with the classical PI control algorithm, the self-tuning PI control algorithm based on the BP neural network has improved the dynamic response characteristics of $U_{s}$ and reduced the response time when the grid voltage drops $0.1 \mathrm{pu}$. When the fault is cleared after $0.5 \mathrm{~s}$, the system recovers stability and the terminal voltage recovers the pre-fault state with a fast and a smooth response for self-tuning PI control algorithm.

When the grid voltage drops $0.15 \mathrm{pu}$ at $t=5 \mathrm{~s}$ with a duration of $0.5 \mathrm{~s}$, the dynamic change diagram of rotor current $I_{d r}$ is shown in Fig. (12). The solid line corresponds to the selftuning PI control algorithm based on the BP neural network and its tuned parameters are $K_{p}=1.25$ and $K_{i}=200$. The dot- 


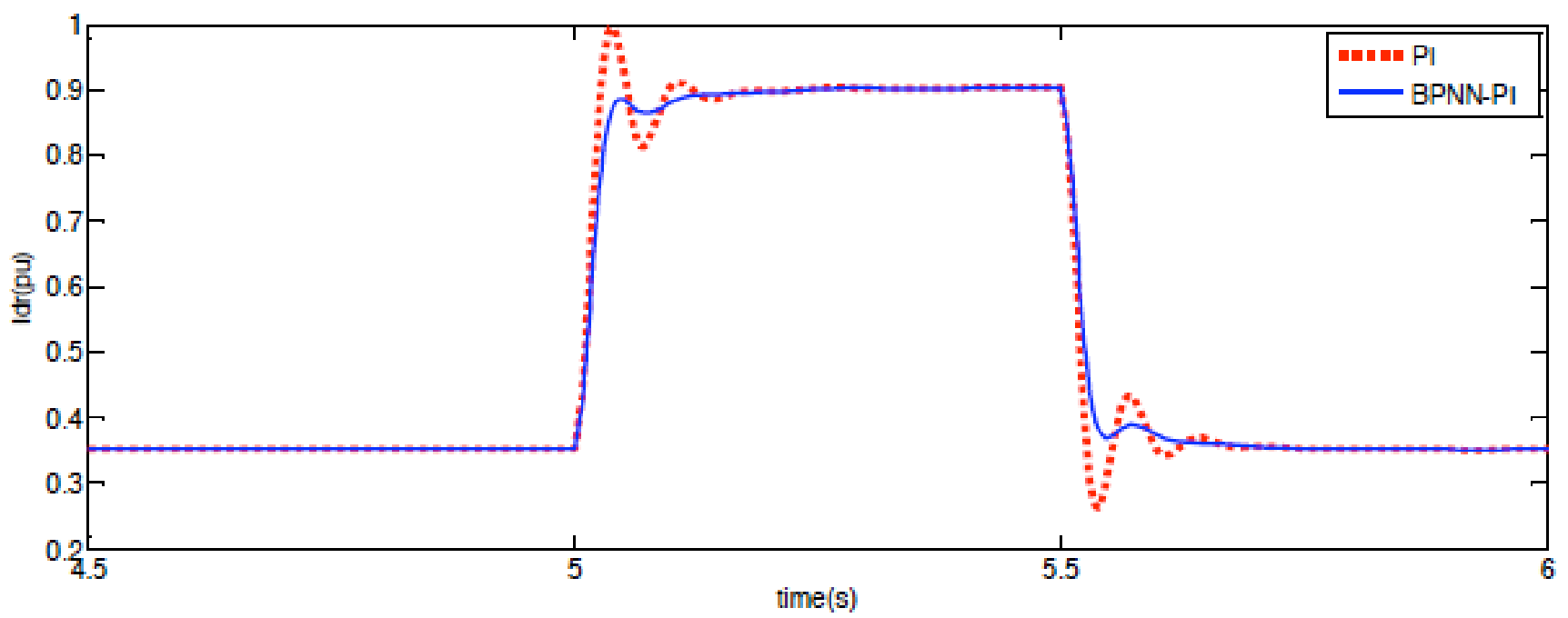

Fig. (12). The dynamic change diagram of $I_{d r}$ when the grid voltage drops $0.15 \mathrm{pu}$.

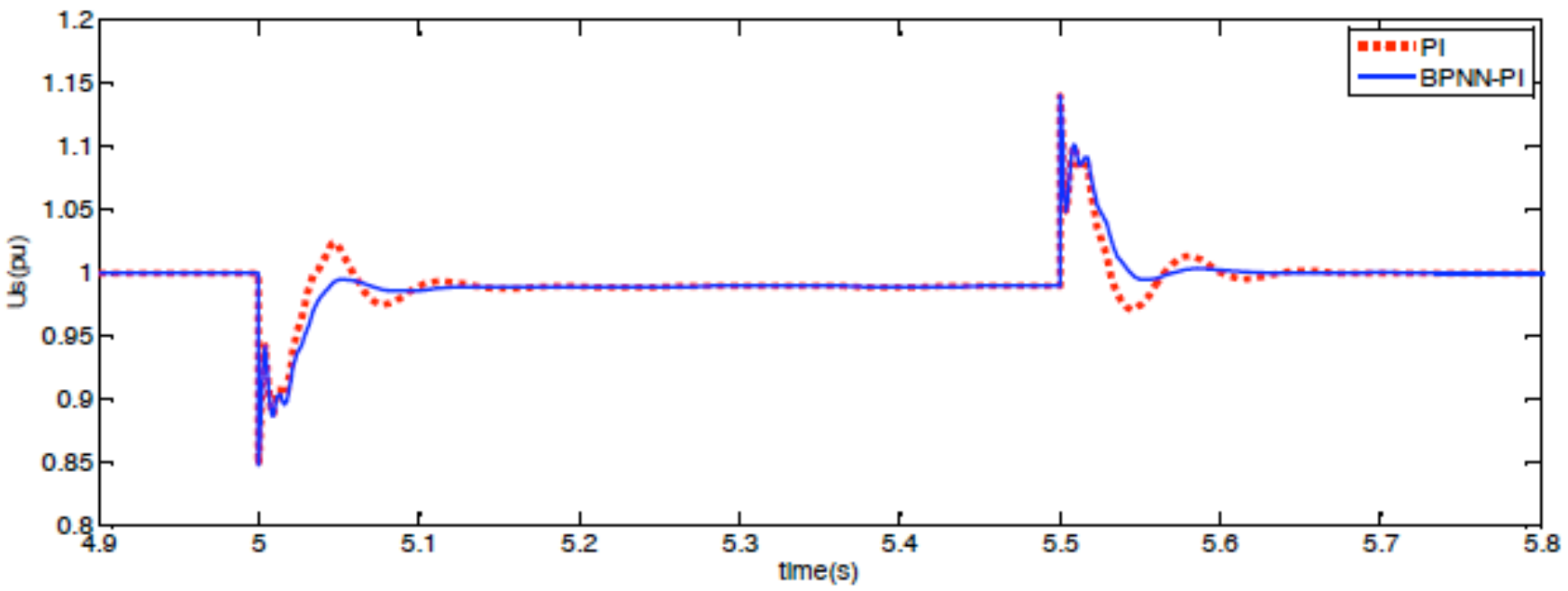

Fig. (13). The dynamic change diagram of $U_{s}$ when the grid voltage drops $0.15 \mathrm{pu}$.

ted line corresponds to the classical PI control algorithm and its parameters are $K_{p}=1.25$ and $K_{i}=300$.

The simulation results show that compared with the classical PI control algorithm, the self-tuning PI control algorithm based on the BP neural network has improved the dynamic response characteristics of $I_{d r}$ and reduced the response time when the grid voltage drops $0.15 \mathrm{pu}$. When the fault is cleared after $0.5 \mathrm{~s}$, the system recovers stability and the rotor current recovers the pre-fault state with a fast and a smooth response for self-tuning PI control algorithm.

When the grid voltage drops $0.15 \mathrm{pu}$ at $t=5 \mathrm{~s}$ with a duration of $0.5 \mathrm{~s}$, the dynamic change diagram of terminal voltage $U_{s}$ for wind turbines is shown in Fig. (13). The solid line corresponds to the self-tuning PI control algorithm based on the BP neural network and its tuned parameters are $K_{p}=1.25$ and $K_{i}=200$. The dotted line corresponds to the classical PI control algorithm and its parameters are $K_{p}=1.25$ and $K_{i}$ $=300$.

The simulation results show that compared with the classical PI control algorithm, the self-tuning PI control algorithm based on the BP neural network has improved the dy- namic response characteristics of $U_{s}$ and reduced the response time when the grid voltage drops $0.15 \mathrm{pu}$. When the fault is cleared after $0.5 \mathrm{~s}$, the system recovers stability and the terminal voltage recovers the pre-fault state with a fast and a smooth response for self-tuning PI control algorithm.

\section{CONCLUSION}

In this paper, on the basis of the steady-state mathematical model of the doubly-fed wind turbine, the vector control method of stator flux oriented is used to achieve a decoupling control of power. By studying the basic principle of the constant voltage control system, the self-tuning PI control algorithm based on BP neural network has been proposed. Building a simulation model of the system, the simulation results show that compared with the classical PI control algorithm, the self-tuning PI control algorithm based on BP neural network has improved the dynamic response characteristics of the rotor current component and terminal voltage, and reduced the response time in case of the wind speed change and grid voltage sag. The stability of grid-connected voltage of wind turbines has been improved. 


\section{CONFLICT OF INTEREST}

The authors confirm that this article content has no conflicts of interest.

\section{ACKNOWLEDGEMENTS}

Declared none

\section{REFERENCES}

[1] Y. F. Ren and Z. Q. An, "The flexible grid-connected operation and control of the doubly-fed wind turbines", China Machine Press, Beijing, China, 2011.

[2] A. Thomas, "Wind Power in Power Systems", John Wiley and Sons, Ltd, New York, UK, 2005.

[3] T. Senjyu, N. Sueyoshi, R. Kuninaka, K. Uezato, H. Fujita and T. Funabashi, "Study on terminal voltage and power factor control of induction generator for wind power generation system" In International Conference on Power System Technology, November 21-24, 2004, Singapore, Singapore.

[4] Y. F. Fan, Q. Chao and Y. Gao, "Simulation of influence of large double-fed variable speed wind turbine into grid", Power System Protection and Control, vol. 36, no. 16, pp. 30-32, 2008.

[5] Z. J. Yang, H. B. Wu and M. Ding, "Control strategy of doubly-fed wind generation system for power grid fault", Power System Protection and Control, vol.38, no. 1, pp. 14-18, 2010.

[6] H. S. Ko, S. Bruey, G. Doumont, J. Jatskevich, and A. Moshref, “ $A$ $P I$ control of DFIG based wind farm for voltage regulation at remote location" Proceedings of 2007 IEEE Power Engineering Society General Meeting, June 24-28, 2007, Tampa, FL, USA.

[7] D. X. Zhang, "Research on the voltage stability control for wind turbine group based on dynamic reactive power compensation"
Power and Energy Engineering Conference (APPEEC), March 2831, 2010, Chengdu, China.

[8] F. Mwasilu, J. J. Justo, K.-S. Ro and J.-W. Jung, "Improved of dynamic performance of doubly fed induction generator based wind turbine power system under an unbalanced grid voltage condition", IET Renewable Power Generation, vol.6, no. 6, pp. 424434, 2012.

[9] J. Kearney and M. F. Conlon, "Control of double fed induction generator wind turbine during network voltage unbalance conditions", Universities Power Engineering Conference (UPEC), September 1-4, 2008, Padova, Italy.

[10] X. G. Zhang, W. M. Wei and Y. C. Liu, "Improved grid voltage control strategy for wind farms with doubly-fed induction generators connected to distribution networks", Journal of Power Electronics, vol.12, no. 3, pp. 495-502, 2012.

[11] M. S. Sarkhanloo and A. S. Yazdankhah, "A new control strategy for small wind farm with capabilities of supplying required reactive power and transient stability improvement", Renewable Energy, vol. 44, no. 32, pp. 32-39, 2012.

[12] R. Li, F. Tang, Y.P. Liu and Y.Q. Ke. "Improved constant voltage control strategy of doubly-fed induction generators based wind farm", Power System Protection and Control, vol. 40, no. 6, pp. 7985, 2012.

[13] A. L. Olimpo, J. Nick, E. Janaka, C. Phil and C. Michael. "Wind Energy Generation: Modeling and Control". A John Wiley and Sons, Ltd, New York, USA, 2009.

[14] K. Åström and T. Hägglung, "Advanced PID Control, Instrumentation", Systems, and Automation Society, Chicago, USA, 2005.

[15] T. H. Martin and B. D. Howard, Neural Network Design, PWS Publishing Company, Boston, USA, 2002.

[16] M. Iulian and C. Nicolaos-Antonio, "Optimal Control of Wind Energy Systems", Springer Publishing Company, New York, USA, 2008.

[17] J. K. Liu, The advanced PID control and MATLAB simulation, Electronic Industry Press, Beijing, China, 2004.

Received: May 19, 2013

Revised: October 05, 2013

Accepted: October 23, 2013

(C) Gu et al.; Licensee Bentham Open.

This is an open access article licensed under the terms of the Creative Commons Attribution Non-Commercial License (http://creativecommons.org/licenses/by-nc/3.0/) which permits unrestricted, non-commercial use, distribution and reproduction in any medium, provided the work is properly cited. 